\title{
MANAGERS FOR SUSTAINABLE ELECTRIC POWER INDUSTRY OF TOMORROW
}

\author{
L. D. GITELMAN, L. M. GITELMAN \& M. V. KOZHEVNIKOV \\ Department of Energy and Industrial Management Systems, Ural Federal University, Russia.
}

\begin{abstract}
To be able to lead a large-scale technological overhaul of the electricity generation sector and actively operate in energy markets, it is necessary to substantially increase the professional level of management. Moreover, there is no doubt that the social responsibility of power engineering as a vital infrastructure industry will only continue to increase, competition will intensify while the existing shortage of knowledge will grow. This is happening amid overall instability, uneven and chaotic demand for energy on the part of economic systems. On the other hand, energy consumers, investors and society as a whole are putting an increasing emphasis on reliability, pricing transparency and environmental impacts. The study provides substantiation and a new research and methodology platform for forward-looking education of energy managers. Its purpose is to equip professionals with knowledge and competencies that they will need for working in emerging technological and organisational and economic systems that will be based on new principles and will function in a turbulent external environment. The global energy education is used as an example of building educational content and methodology for the forward-looking training of future energy leaders.

Keywords: anticipatory training, global energy education, managerial education, power industry, proactive management, sustainability.
\end{abstract}

\section{INTRODUCTION}

Without any doubt, social responsibility of the electric power industry as a vital infrastructure industry will be growing. Moreover, competition among countries for resources will be getting tougher; innovative development will be speeding up and demand for knowledge will be growing. All this is already happening amid uncertainty and aggressiveness of the environment, accelerating changes of absolutely different kinds, irregularities and randomness in electricity-consuming systems. On the other hand, demand of energy consumers, investors and society in general for power supply reliability, transparency of pricing and reduction of the environmental impact is growing.

Politicians, authorities, management of both energy suppliers and energy consuming organisations will pay more and more attention to the problem of sustainable power supply [1].

From a scientific perspective, there is an interest in research into the field of anticipatory management and, consequently, into anticipatory professional training as instruments of ensuring the sustainable development of the electric power industry. It becomes obvious that in order to manage a major technological overhaul of the electricity production sector by introducing Smart Grid systems and to operate proactively in increasingly globalized energy markets, it is necessary to considerably improve the professional capabilities of managers.

\section{RELEVANCE OF ANTICIPATORY MANAGEMENT IN THE ELECTRIC POWER INDUSTRY}

New conditions and factors of the environment that the power industry exists in call for adequate managerial decisions at all levels of management and act as challenges. They can either open new sources of development and efficiency growth, or transform into corresponding threats. 
Challenges arise from time to time as a result of rather powerful financial and economic, scientific and technical factors as well as factors relating to resources, energy and even the nature and climate. For instance, financial and economic crises tend to reduce demand for electricity and result in mass outflows of investments, which impede technical development of the power industry and leads to the wearing out of energy facilities. High volatility in prices for hydrocarbons (natural gas and oil) affects investments and plans for the power industry development.

The re-assessment of available oil and gas reserves and the change of the geography of supplies may require a revision of the entire structural policy in the power industry.

A decrease in the number of opportunities for site selection creates serious problems for the construction of large-scale hydroelectric and nuclear power plants.

Persistent climate change tends to both narrow and expand opportunities for the development of renewable energy sources.

Of course, scientific breakthroughs in the field of energy technology, especially those that have reached the stage of commercial innovations, have a potential for drastically increasing functional qualities and public efficiency of the power industry. They, however, often require a major reconstruction of the grid, changes in the structure of operational dispatch management and the introduction of new models of the competitive electricity market as well as a serious reconfiguration of control systems.

The above-mentioned phenomena are transforming the structure of the power industry and shaping technological solutions. For example, one can see an increase in the share of renewable energy sources in generating capacity in a number of countries; creation of renewable energy storage systems; development of small-scale (distributed) power generation; Smart Grid systems; nuclear power units of small and medium capacity with intrinsically safe reactors.

The growing number of challenges and their crucial role in power industry development have resulted in a relevant intellectual reaction: the role of proactive management and anticipatory training as a response to these challenges has grown.

In fact, it is a question of building a completely new model of development management for the power industry and related industries and sectors: energy consumers, suppliers of primary energy sources and energy equipment, investment services and skilled staff.

Proactive management in the power industry is a set of technical, organisational, resource and economic measures that are implemented at all levels of management and aimed at preventing the negative impact of internal and external factors (including environmental turbulence and limited resources) which threaten the stability, integrity, economic efficiency of the industry, energy companies' competitiveness and power supply reliability.

At the level of the power industry, it means having a state energy policy (strategy), which determines technical development of the power industry, supply-demand balance and energy markets; mechanisms of reliability and safety control as well as methods of energy price regulation.

At the corporate level and the level of the energy facility, it means the strategy of integrated support and development of functional performance in all aspects of operation while minimising dependence on external factors. In addition, the management should focus on the quality and efficiency of use of all kinds of resources: equipment, fuel, finances, investments and human resources. This work should be done regularly based on continuous monitoring of the overall condition of energy facilities. The measures may include an optimal choice of fuel suppliers, engineering services providers and other contractors and their diversification; interaction with educational institutions for staffing assistance; introduction of a progressive system of equipment repair service; interaction with consumers (demand-side management). 
At the level of the system operator, it involves the monitoring of the system reliability; improvement of methods of reserves management, which includes work with major consumers, adjustment of the approach to allocation and optimisation of reserve volumes; contracts for major construction works: the strengthening of electric connections between power grids; the construction of new types of peak power plants; overall automation of reserves and mode controls.

\section{CHANGES IN PROFESSIONAL EDUCATION ARE VITAL}

Introduction of the proactive management model is impossible without appropriate new competences, which calls for radical changes in the professional training of managers. The authors believe that the upcoming changes will include the following components.

1. A new generation of managers in the power industry will participate in the introduction of new technologies and creation of new energy markets. The main changes will be connected with safety, reliability and systems ensuring sustainability, energy saving solutions, introduction of Smart Grid systems and distributed power generation, as well as a variety of economic tools for working with energy consumers. In their turn, major technological innovations tend to trigger deep organisational transformations and a radical change of principles of energy facilities repair and maintenance. Managers will need new qualities and competences:

- Making strategic decisions based on global trends and multiple-factor risks.

- Organisation of innovative processes.

- Management of complex energy projects and programmes.

- Cross-disciplinary team work.

- Good skills in virtual communication, international experience.

2. Educational models are drastically changing towards the acquisition of skills of professional behaviour and proactive actions under the conditions of uncertainty; the need to work with enormous arrays of information which is often contradictory; global networking; monitoring of the latest technological solutions in energy, telecommunications and management. Such models should be based on anticipatory training by which the authors mean an organised process of nurturing knowledge and competences which match global trends and national development programmes.

3. The method of teaching that motivates managers to acquire new knowledge, nurtures mental flexibility and readiness for changes is becoming a priority. An activity approach, event modelling depending on the speed of development of various trends and weak signals as well as project teaching are inseparable elements of anticipatory managerial training, the main focus being on the renewal of knowledge and its prompt application rather than on knowledge acquisition.

In the authors' opinion, managers will be able to efficiently work in the industries with super complex technologies that are potentially dangerous to the global ecosystem if they come to grips with complex correlations between equipment, economy, environment and human factor. Managers need to possess diverse professional knowledge in combination with unique technical and technological specifics, unprecedented responsibility and functions of this particular industry in the economy.

So, the electricity market follows a certain pre-set algorithm that is strongly dependent on the technological peculiarities of power generation and security restrictions. The production plan 
is determined by the operating mode of generating and grid capacities, the specialisation of power plants in the power system load curve and directions of the operational dispatch management. When considering costs and pricing, one should take into account the factors that influence the efficiency of power plants and technological regimes of their operation in the grids. Strategic management also has quite specific tools: creation and maintenance of strategic reserves of capacity, flexibility of power generation to eliminate uncertainty in the electricity load curves; energy companies' technical policy as regards the renewal of fixed assets; demand side management and reliability management.

There are more examples illustrating the great influence of technology on business results and power supply reliability. Power supply reliability takes precedence over financial efficiency; it is standardised by energy regulating bodies and regulated by the grid operator as regards current regimes. One can make a firm conclusion that the decisive influence of the power industry's technological features and the overriding priority of ensuring readiness to carry loads and maintain working efficiency of the equipment are reflected in all areas of the economy and management in the power industry. That is why technical and economic training is the stepping stone for nurturing managers' competences. Managerial decisions should be adequate to technical facilities of power generation; moreover, they should contribute to its improvement.

At the same time, changes relating to the specific issues of electrification for the new Industry 4.0 and the introduction of Smart Grid are becoming essential for the technical and economic education of managers [2]. These circumstances drastically change the entire philosophy of interaction between energy generating and energy consuming systems. An active consumer, who is in fact an absolutely new player in the energy market commissioning services on certain terms, is emerging [3]. So it stands to reason, that managers need to be aware of the new rules of energy markets.

Due to new conditions of functioning and development of the power industry, there is demand for managers who are aware of the methods helping to ensure the following functions.

- Designing of organisational-economic systems with new innovative characteristics and stabilising elements (electricity markets; mechanisms of market regulation of markets, prices and investments; management systems for energy companies; methods of energy companies' interaction with consumers; organisational and economic aspects of the national strategy in the power industry).

- Organisation of a strategic process in energy companies and sectoral or state regulatory bodies, including proactive actions aimed at stabilising the strategy and providing for early neutralisation of external threats, risk minimisation, elimination of various restrictions as well as pursuing new opportunities for development.

- Integrated forecasting and foresight studies of key parameters of the object under control, including trends analysis and the setting of long-term goals, identification of challenges and threats in the external environment with assessment of their consequences.

Selection of innovations which can be obtained from foreign partners, and their adaptation with account to the operational features of the national power industry.

\section{THE ESSENCE OF ANTICIPATORY TRAINING}

Anticipatory training is a progressive kind of the educational process (or its component) which envisages specialists acquiring knowledge and skills (competences) for work in 
technical and organisational-economic systems to be created in the near future which are characterised by high turbulence.

Anticipatory training is provided in a specialised academic environment and it sets the vector of knowledge required for creating a new look of the power industry (energy company) which will embody the forefront achievements of the technological progress and organisational and economic innovations that ensure an optimal balance of commercial and social efficiency of the power industry and include stabilising mechanisms which protect businesses from external challenges and threats. Unlike traditional training of managers who tend to deal with routine (tactical) tasks in energy companies, anticipatory training has a goal of creating a new type of managers: innovators with the competency of being a conceptual designer of new systems and their implementation in the current production process.

An important advantage of anticipatory training is that the learning process includes the modeling of real-life situations in the power industry which enables students to acquire practical skills of proactive management. Within the framework of the traditional approach to the training of managers, they come across such situations only when they start work in an energy company and have to react to the situation after it has occurred, that is, after a time delay. They tend to react spontaneously and intuitively, using the trial-and-error method which does not provide for effective solutions and may, on the contrary, cause the crisis to aggravate.

Other features of anticipatory training include:

- A high level of knowledge provided.

- Educational materials are rich in scientific information, methodology of research work and innovation management, analysis of progressive solutions in the field of innovative management in the power industry.

- The training incorporates the study of mechanisms of scientific and technical interaction with foreign countries and companies within the context of globalisation of the power industry and energy business.

- New principles of organisation of educational process.

The key components of anticipatory training are:

(a) Methodology of developing integrated and science-based technical and organisationaleconomic systems that are rich in innovative elements. For instance, a grid with fulling automated controls reaching down to the consumer level which possesses structural flexibility to absorb new elements based on up-to-date information technologies.

Another example is the wholesale electricity market with automatic protection against rule violation by market participants, with pricing mechanisms matching the efficiency of power generation, transmission and use, with strong motivation for attracting investments in the construction of new energy facilities;

(b) Global trends in technological progress and academic research that could be applied in the power industry.

For instance, distributed power generation; Smart Grid; safe nuclear power plants; economically competitive renewable energy sources; the multi-model concept of the wholesale and retail electricity markets;

(c) Forecasts for resource restrictions and turbulence of the external environment: personnel, fuel, financial and currency volatility, etc.

(d) Genesis of promising and dead-end research projects (based on technical characteristics of energy efficiency, durability, safety and monetary evaluation of competitiveness in 
comparison with traditional power plants).

(e) Proactive management methods capable of neutralising the turbulence of the external environment, overcoming resource restrictions and stabilising competitiveness (financial and economic efficiency) of energy business.

\section{GLOBAL ENERGY EDUCATION}

It is obvious that changes in the content of professional education will match present-day innovative directions of the power industry development. These directions are getting increasingly determined by international integration which is taking on global features. Globalisation processes in the power industry underlie the trend and include:

1. Creation of large-scale electric power grids and pipeline systems running across several countries that each has its own economic and political interests, sometimes contradictory and changeable; these systems should work in accordance with unified technical standards.

2. Shaping of cross-national energy markets functioning amid high risk and uncertainty as regards energy demand, prices, investment resources.

3. Tougher environmental requirements to be met by the world power sector. This is a global trend which has a largely restrictive character in addition to its progressive nature.

4. Occasionally emerging destabilising political and economic factors, including those arising from the instability of the structure of energy exporters and importers.

5. Fast expansion of new rather expensive energy technologies and methods of energy industry organisation which have not been properly assesses in terms of their efficiency under specific application conditions.

Globalisation of the power industry lays the foundation for risk minimisation due to the expansion of the energy-economic space and the application of unified standardisation and management methods; levelling of prices for final consumers at the economically optimal level; the use of identical reliability and safety norms for energy facilities; creation of mechanisms to enable low-income categories of the population to get access to electricity.

Successful implementation of international integration calls for solutions to multi-dimensional problems: ways of settling conflicts of interests, including geopolitical ones, between some countries; taking into account the local context of adaptation of technologies to the existing structure of generating capacities and the grid, organisation of energy markets; the condition of the economy and living standards of population; unification of national technical regulations and environmental standards.

Consequently, an approach to professional education that nurtures a new quality of management in the power industry is becoming much-needed. The analysis of Master's programmes in universities across the world shows an increased focus on this range of problems [4-8]. At the same time, one can notice that the use of anticipatory training, its content and methods, which are topical for the global energy business, are not properly reflected in universities' syllabus.

Based on the research results, the authors recommend the following solutions for discussion by the expert community: 
1. It should be kept in mind that anticipatory training is impossible without integration of a special-purpose research component in the academic process: context analysis, monitoring of technological advances, foresight of competences and structural changes in the economy (energy consuming systems).

2. Learning materials must be rich in scientific information, methodology of research and innovation management, progressive solutions in the sphere of engineering and management. Moreover, it should be done against the background of the energy markets globalisation. This point is confirmed by empirical results of polls of students, teachers and energy company managers (Figs 1 and 2).

3. The scale, novelty and complex nature of the set tasks contribute to the strengthening of ties with the real power industry - the creation of 'smart' partnership: education-sciencebusiness (Fig. 3).

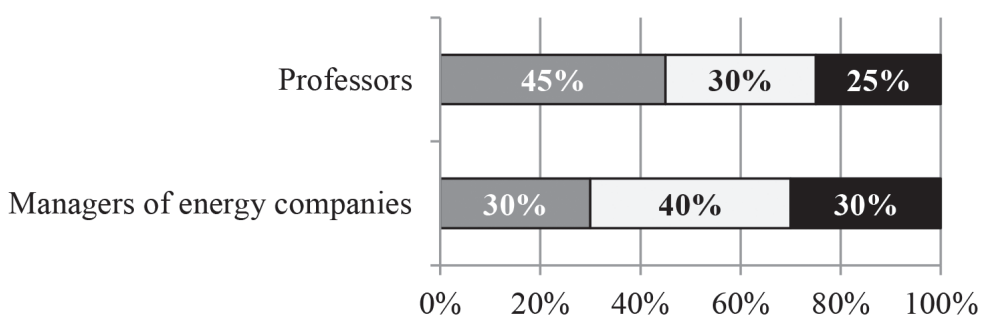

$\square$ Visits to innovative platforms, interdisciplinary discussions with experts, organizational and activity games, strategic sessions, practice

口Forward-looking education

Figure 1: Proportion of educational content in the total volume of Master's programmes for managers.

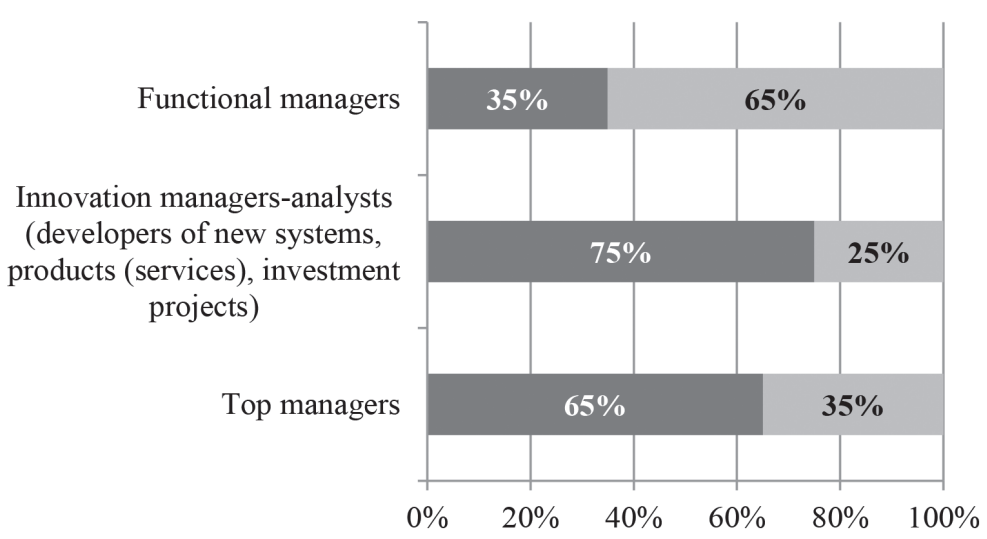

- Proactive competences under conditions of uncertainty and crisis situations

- Competences to perform traditional (operational) tasks

Figure 2: Training of managers of various specialisations. 


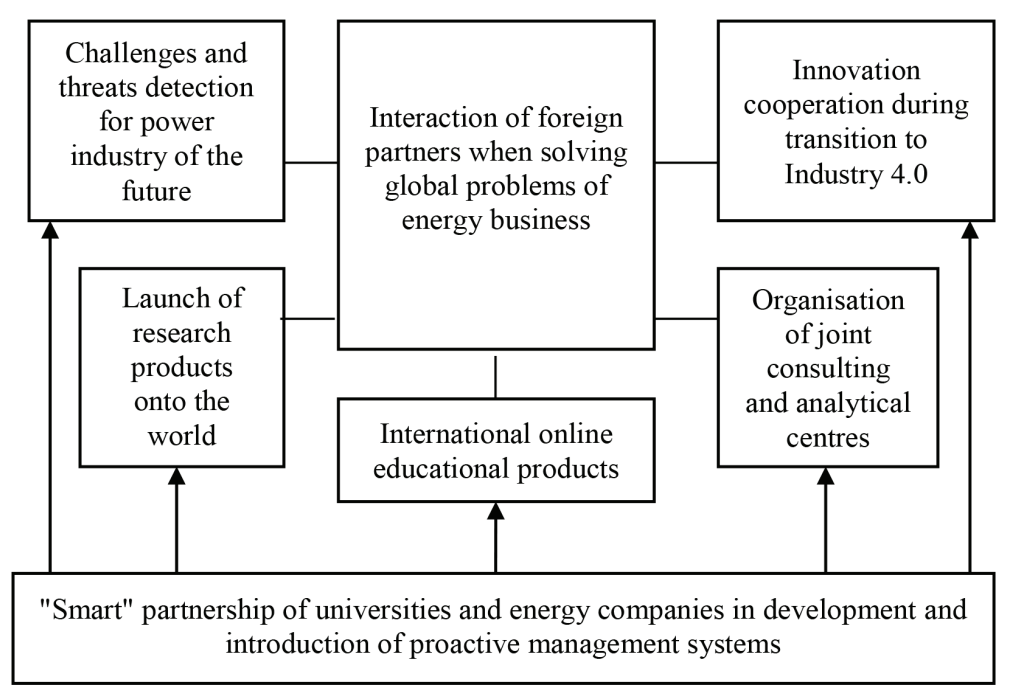

Figure 3: Issues of globalisation of power industry and power business in anticipatory training.

\section{CONCLUSION}

The findings of research that are described in this article lay the groundwork for an emerging area in science - 'Anticipatory professional training for the electric power industry'. Within the framework of this area of research:

- An initial hypothesis, the subject and the object of research were formulated and the methodological framework and the priority agenda of research were developed.

- A technological platform for an anticipatory training toolkit was designed and is being put into practice [9].

- An innovative programme called 'New leaders for technological overhaul of the energy sector' has been created that aims to forge smart partnership between business, university and science. The programme contains specific and tried and tested consulting and academic projects that are of general interest to each party involved in the partnership.

- A New Leaders for Energy engineering school project was implemented that is built upon a completely new model of educational products that meet the challenges of the global market environment.

Conceptual guidelines presented in this article are being introduced at Ural Federal University and in corporate training programmes for energy companies' specialists, thus shaping a system of continuing professional education. Over the years, the authors have participated in the implementation of Master's programmes 'Energy business' and 'Innovation and organisational change management' which are constantly adjusted in line with the methodology of anticipatory training. At present, a new programme, 'Global energy business', has been prepared.

The use of a complex, a system of technologies where each element complements the preceding one and they all are designed in a unified ideological manner (unified methodology, principles, goal orientation, use of electronic resources and network communications platforms) yield a particularly impressive effect. The following technological training complexes 
are being used or have been prepared for introduction: corporate university of innovation type, corporate management incubator, complex of gaming techniques in anticipatory training and conceptual designing, ensuring personnel's readiness for modernisation and organisational changes, mechanism of self-designing of energy company's future, development of energy company's strategy combined with developmental training [10].

\section{ACKNOWLEDGEMENT}

The work was supported by Act 211 Government of the Russian Federation, contract № 02.A03.21.0006.

\section{REFERENCES}

[1] Goldthau, A., The Handbook of Global Energy Policy, John Wiley \& Sons Ltd, 2013. http://dx.doi.org/10.1002/9781118326275

[2] Lorenz, M., Rubmann, M., Strack, R., Lueth, K.L. \& Bolle, M., Man and machine in industry 4.0. How will technology transform the industrial workforce through 2025 ? the boston consulting group report, 2015. Available at: http://www.bcg.it/documents/ file197250.pdf

[3] Volkova, I.O., Gubko, M.V. \& Salnikova E.A., Active consumer: the task of optimizing electricity consumption and own generation, [in Russian]. Problems of Management, 6 , pp. 53-61, 2013.

[4] Anany, M.N., Shehadeh, M.F. \& Pena, C.A., Design of a new egyptian/european double master degree in clean energy and environmental studies. Energy Procedia, 36, pp. 408-417, 2013.

http://dx.doi.org/10.1016/j.egypro.2013.07.047

[5] Benchikh, O., UNESCO's Global Renewable Energy Education and Training Programme, Science Forum 2004, pp. 25-37, 2004. Available at: http://www.fvee.de/ fileadmin/publikationen/Themenhefte/sf2004/sf2004_03_02.pdf

[6] Harrigan, M., Curley, E., Global Environmental Education, Lacking Energy. Available at: https://www.ase.org/sites/ase.org/files/global_environmental_education_lacking_energy.pdf

[7] Malkki, H. \& Paatero, J., Curriculum planning in energy engineering education. Journal of Cleaner Production, 106, 2015, pp. 292-299.

http://dx.doi.org/10.1016/j.jclepro.2014.08.109

[8] Kandpal, T.C. \& Broman, L., Renewable energy education: A global status review. Renewable and Sustainable Energy Reviews, 34, 2014, pp. 300-324.

http://dx.doi.org/10.1016/j.rser.2014.02.039

[9] Gitelman, L.D., Kozhevnikov, M.V., Sandler, D.G., University technology platform of anticipatory learning. Economy of Region, 1, 2016, pp. 257-266. http://dx.doi.org/10.17059/2016-1-20

[10] Gitelman, L.D., Isayev, A., Gavrilova, T., Gamburg, A., Gitelman, L.M., Yeliseyeva, K., Zorin, N., Kozhevnikov, M., Kostina, G., Rostik, O., Uglova, L., Chazov, A. \& Chazova, T., Methodology of Innovative Management Education, Ekonomika Publishing House: Moscow, pp. 54-59, 2015. 